\title{
The Association Between Sports, Body Image, and Eating Disorders of Males Teens at Eastside Catholic
}

\author{
Ruoya Huang ${ }^{1}$ and Stephanie McNesby ${ }^{\#}$ \\ ${ }^{1}$ Eastside Catholic High School, Sammamish, WA, USA \\ \#Advisor
}

\section{$\underline{\text { ABSTRACT }}$}

In the past 25 years, the number of males who are dissatisfied with their bodies increased threefold. This is prevalent especially in the athletic field, where different physique expectations are closely associated with performance. Heightened focus on dietary rules and fitness level cause males to struggle with body dissatisfaction and shame and increase the risk of them developing eating disorders (ED), some of which are the most fatal mental illnesses. Many disordered eating behaviors stem from negative self-perceptions, which start to develop as early as the beginning of grade school and intensifies during pubertal development. However, most studies that examine this issue either looks at female college athletes who have a heavy exercise load and pressure from society on their physiques or focuses on social factors of peer pressure, family influence, and beauty standard. Therefore, it is imperative to determine whether sports participation is positively correlated with the rapidly growing rate of body image issues and ED symptoms in adolescent boys to help address them promptly and prevent severe and lasting damages. This quantitative case study conducted on male teens at Eastside Catholic High School (ECHS) found positive correlations between aesthetic/strength sports, body image issues, and higher ED risks, suggesting that athletic involvement plays a greater role in a person's physical perception and mental health than body weight does. The conclusions inform education institutions and guardians of the more effective way to detect male adolescents' body image issues and eating disorder symptoms, helping to prevent or alleviate mental illnesses.

\section{Literature Review}

\section{Body Image}

In 2014, over 50\% of Americans were unhappy with their weight and appearances (Gallivan, 2014). In recent decades, body image issues have become an ingrained part of the US social norm. Coined by Paul Schiller in 1935, body image is "a multidimensional construct encompassing 1) Beliefs about appearance, including memories and assumption. 2) Feelings about the body, including its size and shape. 3) Perception of the body and the sense of embodiment" (Mountford \& Koskina, 2015). Negative Body image takes many forms: an individual's unrealistic view of one's body (Voelker et al., 2015), feeling bad about one's own body and unconfident of one's attractiveness ("Weight \& Body Image Disorders," 2020), and/or the desire to control and change one's body to the ideal body image perceived (Brazier, 2020). The most common symptoms of having negative body image include 1) Obsessive self-scrutiny in mirrors while feeling inadequate, 2) thinking disparaging comments about one's body, and 3) frequent comparison of one's shape and size to those of others ("Weight \& Body Image Disorders," 2020). The primary cause of negative body image is the internalization of societal physical ideals that shape individuals' perceptions of their bodies and appearances, usually with dissatisfaction (Voelker et al, 2015). Previous studies conducted in the western nations provide consistent empirical support that as the discrepancy between the actual body and the internalized ideal increases, body dissatisfaction intensifies (Izydorczyk et al., 2018), showing it is necessary to explore the internalization of social ideals to address body image issues. A considerable body of literature has recognized the pernicious consequences of 
negative body image. It was found that moderate negative body image can cause anxiety, depression, and a lack of self-confidence and esteem, while extreme negative body image can consume individuals and lead to serious health concerns, including eating disorders ("Body Image," 2018). Thus, body image is an important topic to examine.

\section{The prevalence of negative body image among male athletic adolescents}

The rate of the teen male population who are unhappy with their image increased from $15 \%$ in the 1990 s to $45 \%$ in the 2010s (Team Rawhide, 2016). It was also found that $25 \%$ of male teens with a normal weight think that they are underweight (Team Rawhide, 2016). Previous research shows that differing from teenage girls that usually aim for weight loss, teenage boys often strive for a muscular physique through excessive exercise or supplements (such as steroids or "natural" shakes and powders) consumption (Kypri et al., 2014). The popular pursuit of sinewy body type among male teens in the athletic field is particularly salient because of the heightened focus on athletes' eating habits and fitness levels to improve performance. As a result, more have reported intensified body image issues (Burtka, 2019), indicating the need to explore the association between athletic involvement and body image issues.

\section{Association between different types of sports and body image issues}

Athletes who engage in sports that focus on leanness, including dance, karate, swimming, gymnastics, diving, and running, have more weight control expectations regarding body size and shape than other sports do, and thereby have a greater likelihood of developing unhealthy eating habits (Academy, 2016). Revealing and form-fitting uniforms can also make some athletes more self-conscious of their body imperfection. A previous study found that cross-country runners have the most positive body perception and the highest muscle satisfaction rate whereas football players and wrestlers report the highest muscle dissatisfaction rate and negative attitude towards their bodies (Pavao, 2013). Also, a Dutch study conducted on female athletes found that gymnastics, a typical aesthetic sport, incur more dieting and body image issues than non-aesthetic sports because gymnasts are more likely to link thinness to victory (Bruin et al, 2007). Despite decades of research, few studies examined how different sporting experiences influence the body insecurities of male adolescents.

The association between negative body image of male adolescents and disordered eating behaviors

There exists a considerable body of literature that suggests that adolescents with a higher level of body-dissatisfaction rate have more unhealthy eating habits (McCabe \& Ricciardelli, 2004). The symptoms of eating disorders are more prevalent among youths with negative body perceptions than those that are confident and positive toward their body (Bearman et al., 2006). Body image issue, which is a "disturbance in the way in which body weight or shape is experienced, with the undue influence of body weight or shapes on self-evaluation or persistent lack of recognition of the seriousness of current low body weight" is a primary diagnostic feature of various eating disorders (Mountford \& Koskina, 2015). Therefore, serious body image issues usually come with detrimental eating habits that incur severe mental, psychological, and physical damages. A longitudinal study conducted among 5527 males aged 12 to 18 years old (from 1999 to 2010) found that adolescents with high concerns about muscularity and use supplements (such as protein shakes), substances (such as steroids and growth hormones), and other products to enhance physique are more likely to start binge drinking frequently and using drugs (Kypri et al., 2014). This finding substantiates the claim that correcting unhealthy fitness approaches is crucial to ensuring the health of male adolescents. It should also be noted that the different expectations of the ideal physiques of the two genders require a different research angle for male adolescents. 


\section{Eating Disorders}

Eating disorders are serious mental illnesses that often appear during teen years or young adulthood and last for decades ("Eating Disorders," 2020), so adolescence is a crucial period for detecting and treating them to minimize the harmful consequences. Among the most common eating disorders, anorexia nervosa is the most fatal mental disorder (Insel, 2012). In general, all eating disorders incur severe disturbances in people's eating behaviors, related thoughts, and emotions ("Eating Disorders," 2020). The damages they make vary, ranging from gastrointestinal problems, starvation/malnutrition, medical complications of obesity, suicidal thoughts, and electrolyte imbalance that can lead to stroke or heart attack ("Eating Disorders," 2020). A series of recent studies found the stereotype that only women are prone to eating disorders and the stigma surrounding mental illnesses in general cause men to avoid seeking help from professionals and/or discuss their struggles with others. In fact, 10 million male Americans will suffer from eating disorders at some point in their lives ("Eating Disorders in Men," 2020). However, in their survey of eating disorders in men, Strother, Lemberg, Stanford, and Turberville found that to avoid being perceived as feminine, gay, weak, or weird, males often hide their symptoms and thereby missing crucial treatments from therapists (Strother et al., 2012). Thus, the number of men suffering from abnormal relationships with their bodies and eating habits have grown rapidly in recent decades partly due to the prejudice and stigmas clouding public awareness of eating disorders among males and the inadequate implementation of assistance programs to help address negative body image and eating disorders ("Eating Disorders in Men," 2020). The lack of vital resources and awareness must and can be addressed with empirical evidence that demonstrates the severe consequences of untreated eating disorders incurred by negative body image in men. It would be especially valuable to examine male adolescents because early detection and treatments at the onset of symptoms can effectively minimize the damages.

\section{Methods}

The primary research question of this study is "To what extent does athletic involvement of male adolescents in King County influence their internalization of negative body image perceptions, leading to disordered eating behaviors?" The secondary questions are 1) "How prevailing is negative body image (e.g., anti-fat or anti-thin) prevailing among male athletic adolescents?" 2) "How do different types of sports/activities correlate with individuals' perceptions of their body (aesthetic, strength, etc.) differently?" 3) "What is the association between internalization of negative body image perception of male athletic adolescents and disordered eating behaviors?"

Based on the research on previous works, the following hypotheses were made: 1) The prevalence of eating disorder risks among athletic male adolescence is higher than $5.5 \%$, which is the national average among male adolescents, because studies have shown triggering impacts of athletic involvement (Lipson \& Sonneville). 2) Students who are involved in aesthetic sports (dance, gymnastics, cheerleading, figure skating) are more likely to feel not skinny enough and attempt using dietary rules to achieve and/or maintain lower body weight when they are already in the normal BMI range due to the skinny and lean body expectations for those sports. 3) Students who play sports that require strength (football, weightlifting, bodybuilding, wrestling, rowing and crew) have a stronger desire to build muscles and are prone to using dietary supplements to achieve a masculine physique as bulk body type is usually associated with strength. 4) Both students engaged in aesthetic and strength sports are less confident in their body and have more salient body image issues, though with different expectations. 5) Older participants are more likely to show severer body image issues and eating disorder symptoms because the problem usually intensifies as people grow older. 6) Adolescents with higher BMI manifest greater body image issues and perform disordered eating behaviors more frequently, driven by shame and the desire to become better athletes through altering ones' physique.

To test the hypothesis, the researcher conducted a case study at Eastside Catholic High School (EC), which is a medium-size school that offers 22 athletic teams, and obtained 19 Metro League championships, 12 WIAA academic state championships, and 9 state championships (Eastside Catholic). Due to the difficulty of obtaining a large 
sample in the entire district, the researcher decided to conduct a quantitative case study, which is an intensive, systematic investigation of a single individual, group, or community (Heale \& Twycross) by analyzing the percentage differences between variables (sports, body image, eating disorder).

A survey was constructed to ask participants about their activity level, eating habits, and perceptions of their bodies (See appendix). To get data that reflect participants' body image perceptions and eating behaviors accurately, the questions are formulated based on the Body Investment Scale (BIS) and the Eating Disorder Examination Questionnaire (EDE-Q). The survey consisted of 36 multiple choice questions and one free-response question. Physical activity questions were asked about the students' sports in the past 6 months to ensure the accuracy of the correlation between sports and body perceptions because half a year is the average time for an activity to alter physique notably. Participants were first asked about the sport they have done the most and the frequency of that activity. Then, they answered 12 body-perception questions designed with the Likert Scale. "1" is "do not agree at all," "3" is undecided," and " 5 " is "strongly agree". They then chose the frequencies of themselves performing 18 negative body image and disordered eating behaviors in the past 28 days. The 28-day time frame is designed to evaluate whether a pattern of problematic psychological symptoms is present. The free-responding question was included to collect more detailed information. The survey was distributed using the convenience sampling method through mentor period and social studies courses with the help of schoolteachers. A total of 57 responses were collected from February 5 to March 10, 2021. Google Forms and Microsoft Excel were used for survey creation, data tabulation, and figure creation.

The eating disorder examination questions are organized and analyzed using the Eating Disorder Examination Edition, 17.0 D (Fairburn, Cooper, \& O'Connor, 2014). Participants are identified as having elevated ED risks when they perform $3+$ symptoms of an eating disorder. Statistical correlations between physical activity involvement, negative body image, and eating disorder behaviors were then explored by comparing the percentages. For each finding, the P-value was calculated using Z-test. The average male students, which refers to all participants regardless of sports and weight, are the control group. Strength athletes, aesthetic athletes, obese male students, and underweight male students are the test groups.

Since EC uses English as the primary teaching language, the survey was formulated in English. Informed consent from the participants was obtained before they proceeded to fill out the survey. A pilot test was conducted on two students to fix any confusion and misunderstandings of the questions. All questions are designed to be as clear and simple to understand as possible.

\section{Results}

This study intends to explore the correlations between athletic involvement, body image issues, and eating disorder risks. To put the finding into context, two other demographic factors that have been used in related studies - age and BMI - were also examined for comparison. The following results are organized based on the hypotheses they answer.

Is the prevalence of eating disorder risks among athletic male adolescence at EC higher than $5.5 \%$ ?

In every eating disorder category except moderate bulimia nervosa (severer than mild bulimia nervosa) and binge-eating disorder, students who engage in aesthetic sports perform more symptomatic behaviors than average male students and students who play strength sports. Strength sports players have a higher frequency of having symptoms of all eating disorders except anorexia nervosa and atypical anorexia (both are the restrictive type of ED). Aesthetic athletes also have the highest percentage of attempting weight loss or body shape altercation than the other two groups. It was found that $23.5 \%$ of average male students at EC have symptoms of ED, which is much higher than the national average of the male population (5.5\%) nationwide. $60 \%$ of male aesthetic sports players and $33.33 \%$ of strength athletes at EC manifest elevated ED risks, which are both above the national average as hypothesized. See figure 1. Z-score of 5.345 and a P-Value of $<.00001$ was found for the aesthetic group and a Z-score of 4.048 and a 
$\mathrm{P}$-Value of $<.000026$ for the strength group. Thus, the results are statistically significant, and the null hypothesis can be rejected.

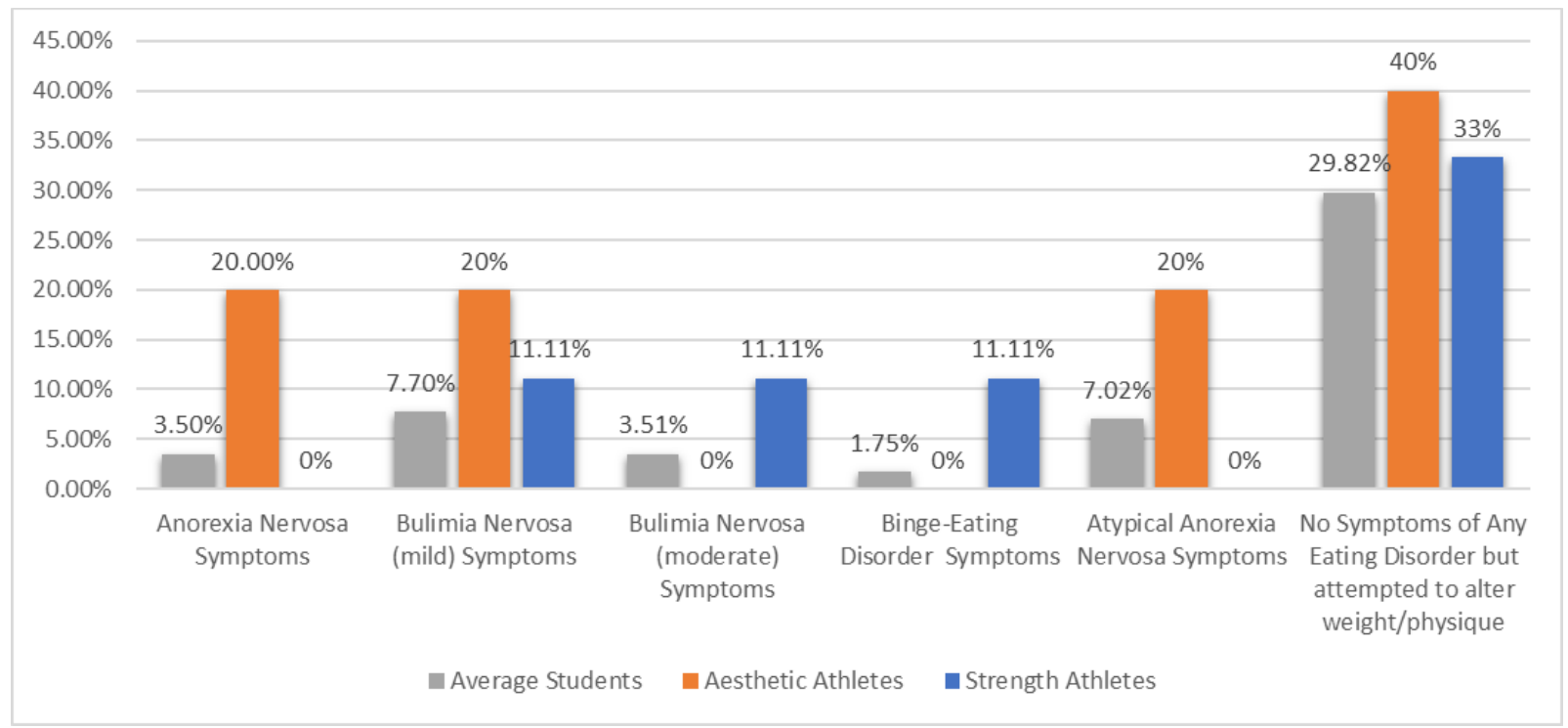

Figure 1: Eating Disorder Symptoms of Average Male students vs Aesthetic Athletes vs Strength Athletes at EC

Average male students have the highest rate $(47.37 \%)$ of not having any symptoms of eating disorders or attempts to change physique whereas no aesthetic athletes $(0 \%)$ are free of those behaviors. Strength athletes' group is in the middle with a rate of $44.44 \%$. See figure 2 . This result that fewer aesthetic athletes and strength athletes are free from eating disorders or physique concerns corroborates the finding that they have higher ED risks than average male students.

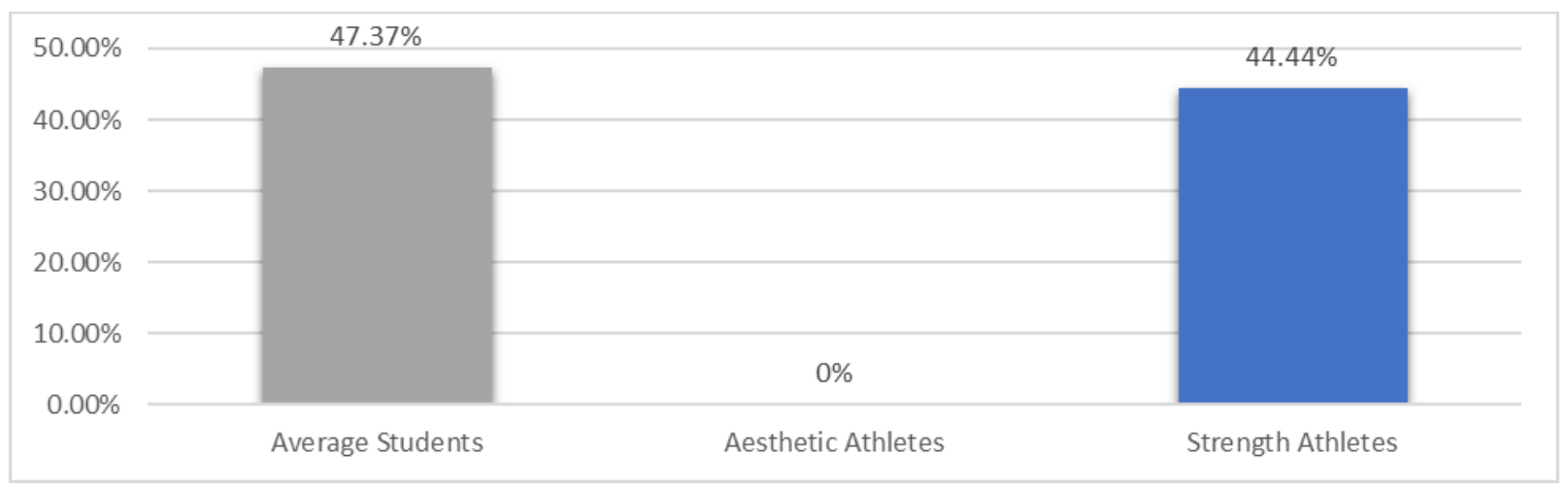

Figure 2: Free From Symptoms of Body Image Related Behaviors (Average Male Students vs Aesthetic Athletes Vs Strength Athletes at EC)

Are students who are involved in aesthetic sports more likely to feel not skinny enough and attempt using dietary rules to achieve and/or maintain lower body weight when they are already in the normal BMI range due to the skinny and lean body expectations for those sports? 
It was found that $60 \%$ of aesthetic athletes are uncomfortable with their bodies, distracted by thinking of disparaging comments about their bodies, and want to achieve an "ideal" body type or shape. $40 \%$ of aesthetic athletes think they are too fat when their body weights are within the normal BMI range, whereas $10.53 \%$ of average male students feel the same way when at healthy weight or underweight (Z-score: 2.572 , P-Value: 0.005056). The null hypothesis can be rejected, so it can be confirmed that aesthetic athletes have more abnormal and unnecessary concerns over their weight than average students. None of the athletes are confident in their attractiveness. $60 \%$ are strongly unconfident. Only $20 \%$ love their body despite the imperfections. See figure 3.

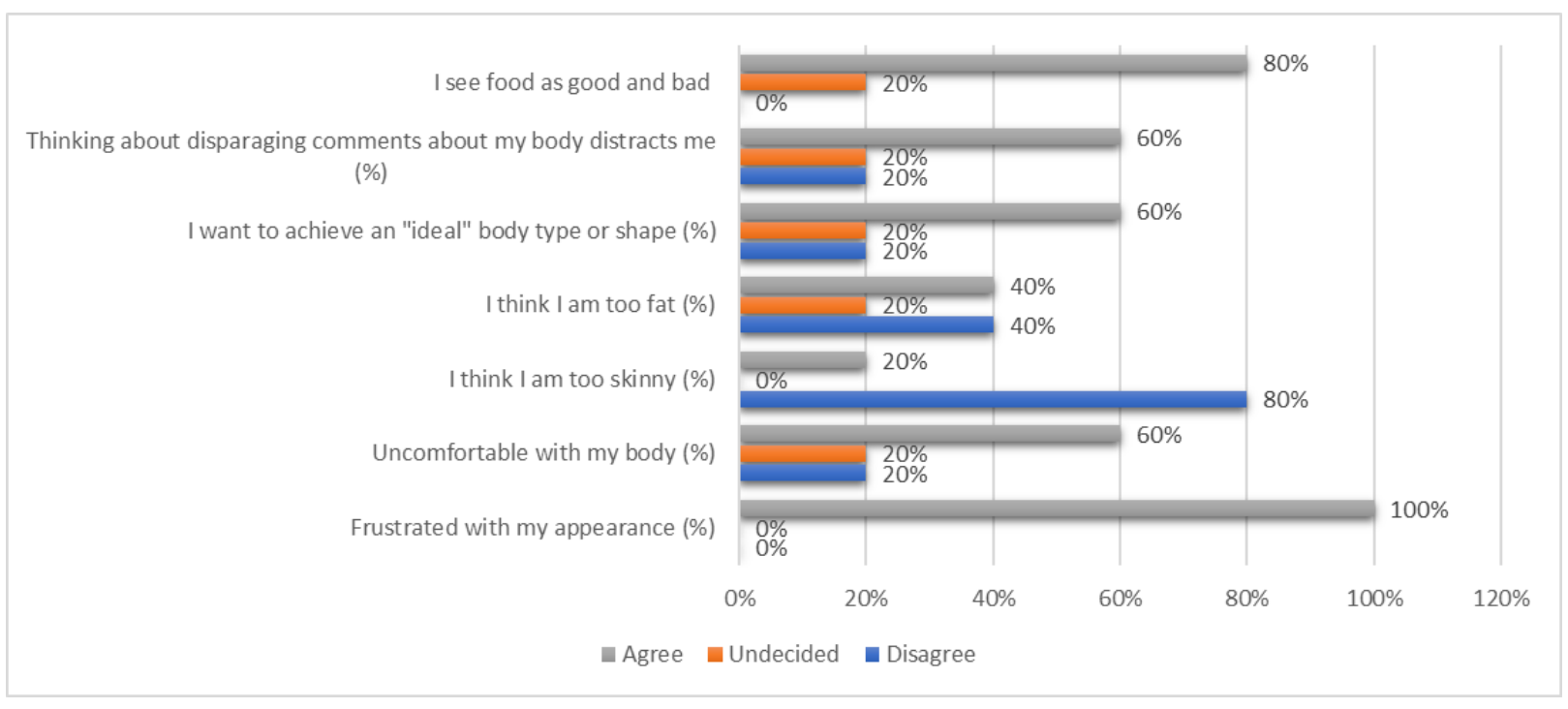

Figure 3. Body Image Perceptions of Male Adolescents at EC (Aesthetic Sports)

Do Students who play sports that require strength have a stronger desire to build muscles and are prone to using dietary supplements to achieve a masculine physique as bulk body type is usually associated with strength?

All nine participants who play strength sports want to achieve an "ideal" body type. $33 \%$ think they are too skinny, are distracted by thinking of disparaging comments about their body and are frustrated with their appearances. $22 \%$ think they are too fat. $77 \%$ feel confident in their attractiveness. See figure 4 . It was found that $66.6 \%$ of them consumed dietary products at least 13 days per 4 weeks and $88.9 \%$ do so at different frequencies, whereas $40.4 \%$ of average male students incorporate dietary supplements in their diet (Z-score: 3.278 and P-value: 0.000523). The null hypothesis is rejected, so the hypothesis that strength athletes tend to use more dietary supplements is confirmed. $44 \%$ still love their bodies in spite of the imperfections, which is $24 \%$ higher than aesthetic athletes. See figure 4 . 


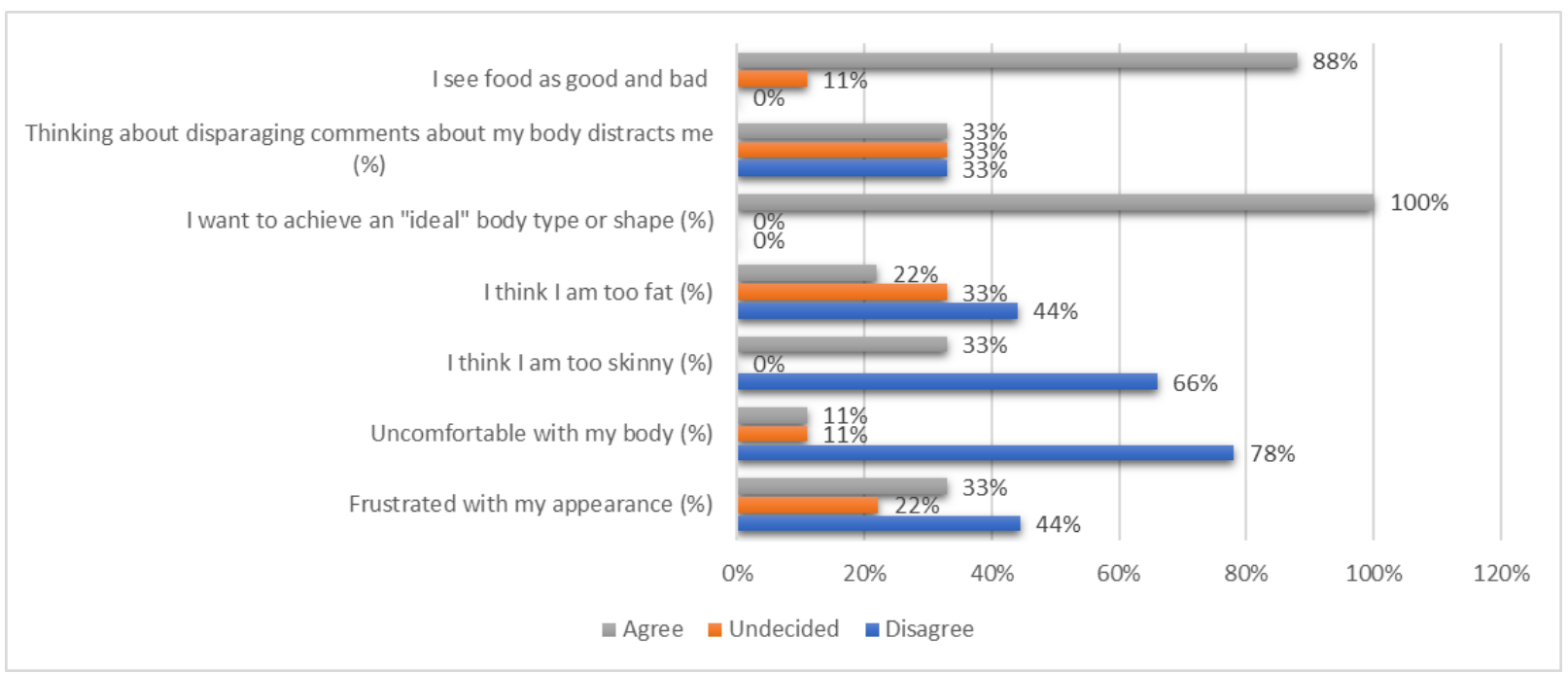

Figure 4: Body Image Perceptions of Male Adolescents at EC (Strength Sports)

Are both students who engage in aesthetic and strength sports less confident in their body and have more salient body image issues, though with different expectations?

More aesthetic sports athletes are frustrated and uncomfortable with one's body (80\%) and distracted by frequently thinking about one's body $(60 \%)$ than average male students. All 5 students who play aesthetic sports are frustrated with their appearances $(100 \%)$, which is significantly higher than the percentage of average male students (25.45\%; Z-score: 3.827, P-Value: .000065). See figure 3 and figure 5. This finding supports the hypothesis that aesthetic sports exacerbate body image issues.

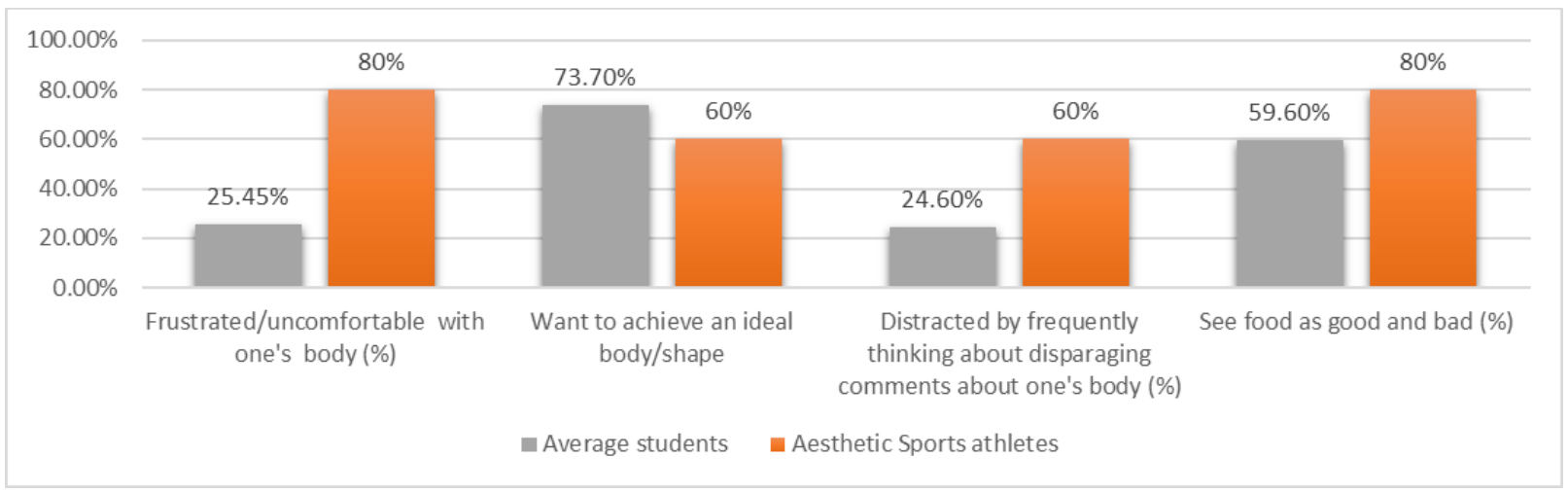

Figure 5: Average Male Students vs. Aesthetic Sports Male Athletes (Body Image Issue)

More strength sports athletes want to achieve an "ideal" body type or shape (100\%) and are distracted by frequently thinking about one's body (33\%) than average male students $(73.3 \% ; 24.6 \%)$. Though average students are more likely to be frustrated and uncomfortable with one's body than strength athletes, they only differ by $3.45 \%$. Strength sports athletes are $8.40 \%$ to $26.3 \%$ more likely to display body image issues range than average students, which matches the hypothesis that strength athletes have more salient body image issues. See figure 6 . 




Figure 6: Average Male Students vs. Strength Sports Male Athletes (Body Image Issue)

Are older participants more likely to show severer body image issues and eating disorder symptoms because the problem usually intensifies as people grow older?

The age difference between adolescents who are 13- to 18-year-old appears to have some influence on body image issues but is not as significant as other factors. Adolescents are similarly frustrated/uncomfortable with their bodies (23\% vs $28 \%$ vs $23.53 \%$; Z-score: 0.052 , P-Value: 0.479304$)$ and desire an ideal body/shape (76.92\% vs $72 \%$ vs $82.35 \%$; Z-score: 0.531 , P-Value: 0.297709 ). The null hypothesis could not be rejected, so no positive correlation could be concluded between age and severity of body image issues among male adolescents. However, older adolescents (17-18) are more likely to be distracted by thinking about disparaging comments about one's body (41.17\%) than younger ones (15.38\% \& 16\%) (Z-score: 2.947, P-Value: 0.001602). See figure 7. The null hypothesis is rejected, so this result suggests older adults might be more sensitive to others' opinions and tend to internalize social ideas to be critical of themselves.

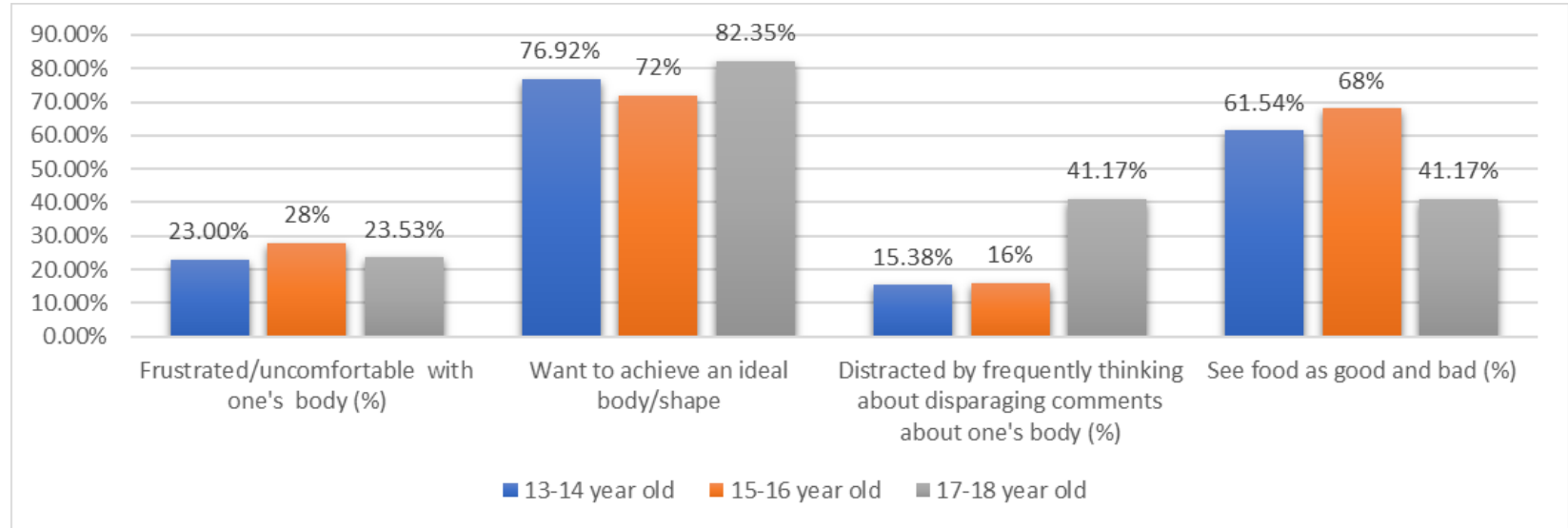

Figure 7: 13-14 vs. 15-16 vs. 17-18-Year-Old Male Adolescents (Body Image Issue)

15- 16-year-old male adolescents $(60 \%)$ at EC are more likely to manifest elevated ED risks than 13- 14year-olds (37.5\%) and 17- 18-year-olds (53\%) do. However, the difference is relatively small, and the trend is inconsistent, showing no statistically significant positive linear correlation between age and eating disorders. 


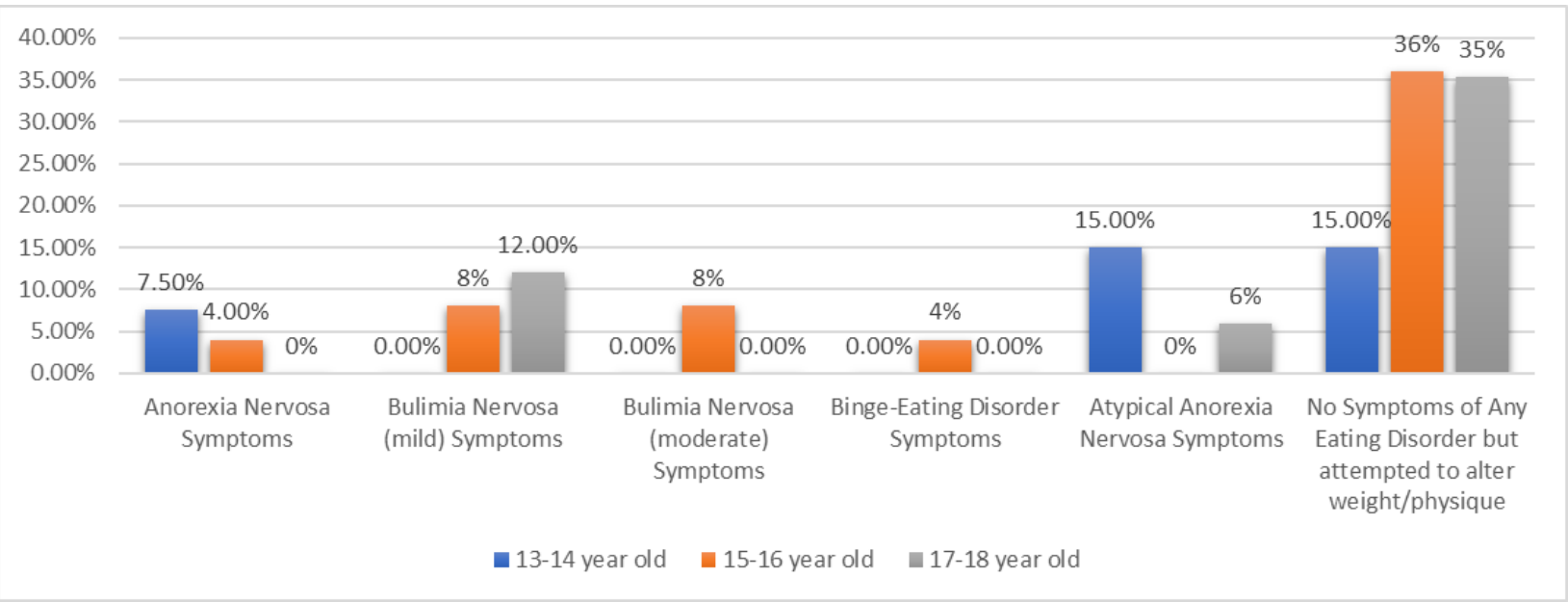

Figure 8: Eating Disorder Symptoms of 13-14 vs 15-16 vs 17-18-Year-Old Male Students at EC

Among all five participants whose BMI scores are in the "Obese" category, 80\% want to achieve an "ideal" body type or shape. $40 \%$ are frustrated with their appearances and $20 \%$ are uncomfortable with their body. Only $20 \%$ are distracted by thinking of disparaging comments about their bodies. Though all participants agree that they are "not too skinny", no one thinks he is "too fat" either. See figure 9.

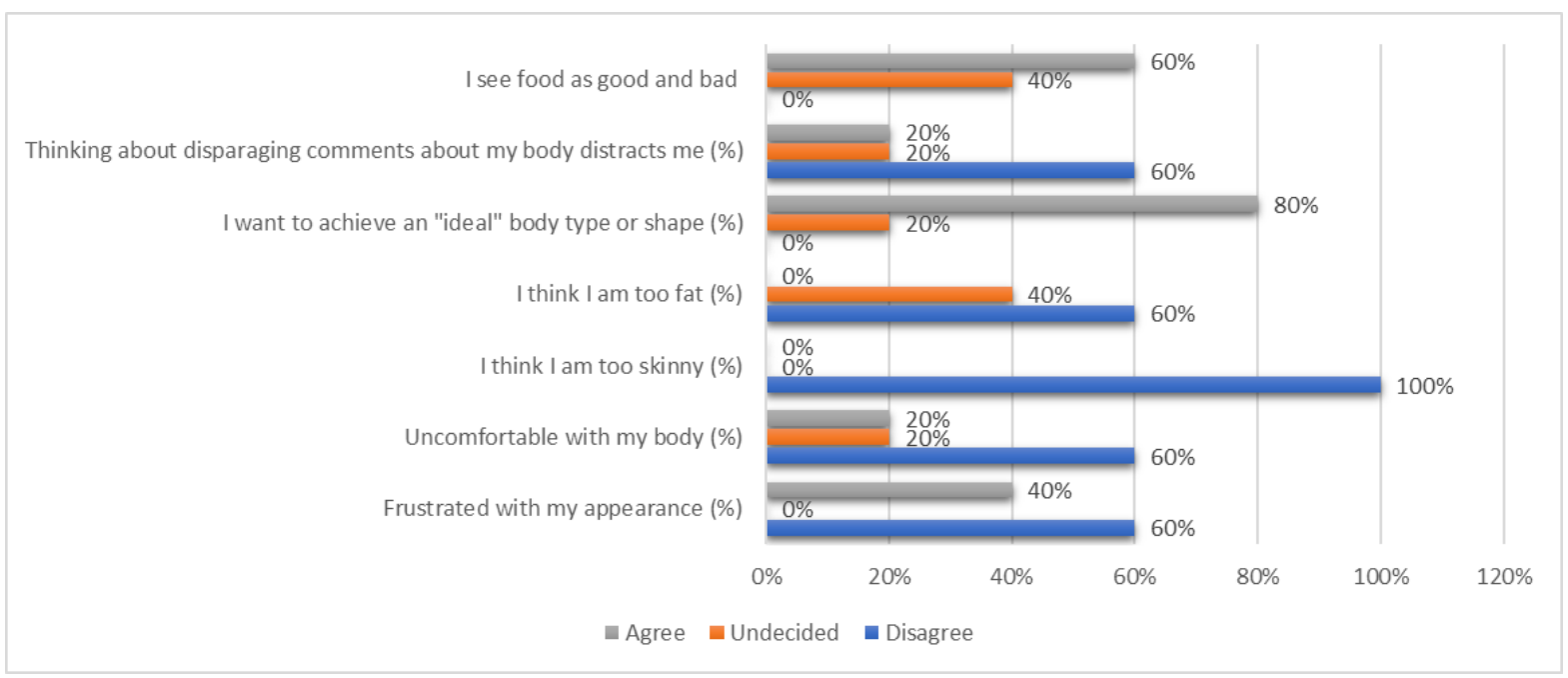

Figure 9: Body Image Perceptions of Male Adolescents at EC (Obese)

In comparison to that of average students, the percentages of obese male adolescents who are frustrated and uncomfortable with one's body (30\% vs 25.45\%; Z-score: 0.234 , P-Value: 0.407687$)$ and want to achieve an "ideal" body type or shape (80\% vs $73.7 \%$; Z-score: 0.320 , P-Value: 0.374522$)$ are higher. However, the P-values are above 0.05 , so the null hypothesis was not rejected. In other words, there is no sufficient evidence to show that obesity engenders more body image issues. Though average male students are more likely to be distracted by frequently thinking about one's body, the difference is minuscule (4.6\%). See figure 10. 


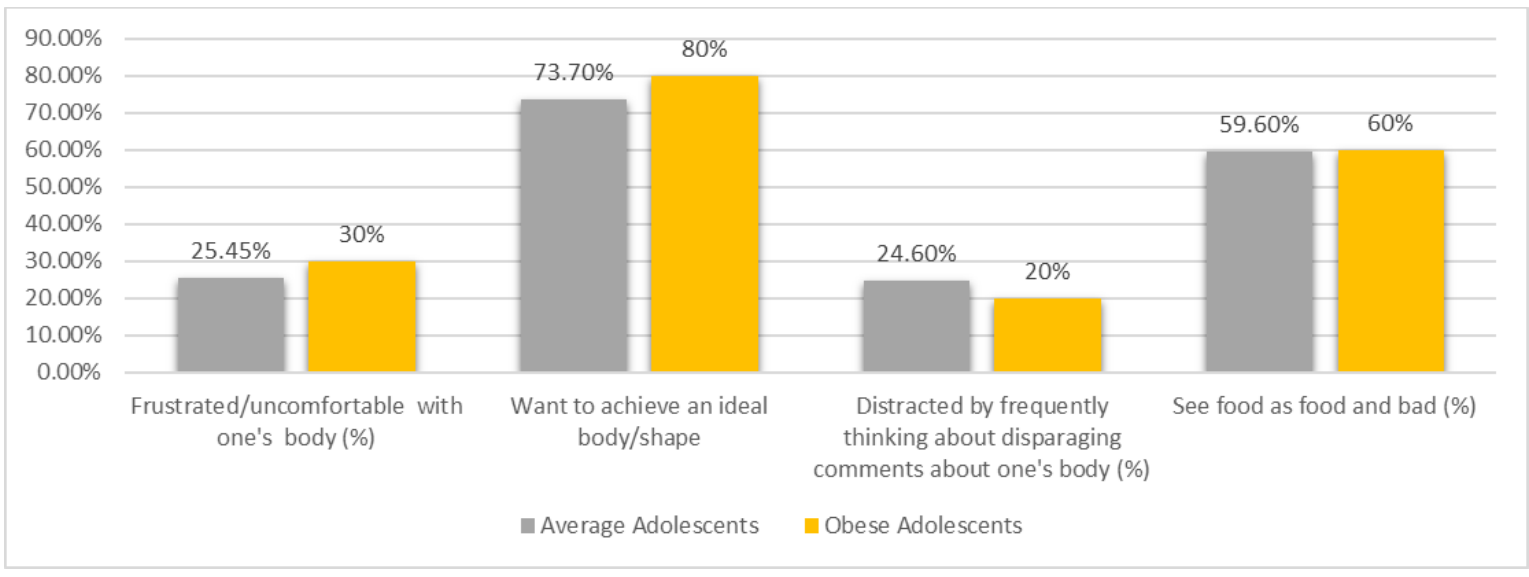

Figure 10: Average Weight Male Students vs. Obese Male Students (Body Image Issue)

Among all 13 students whose BMI values indicate "underweight", 60\% want to achieve an "ideal" body type or shape. $46 \%$ of them are frustrated with their appearances, think they are too skinny and think about disparaging comments. Though being underweight, $15 \%$ of them think they are too fat, displaying abnormal weight concerns. See figure 11 .

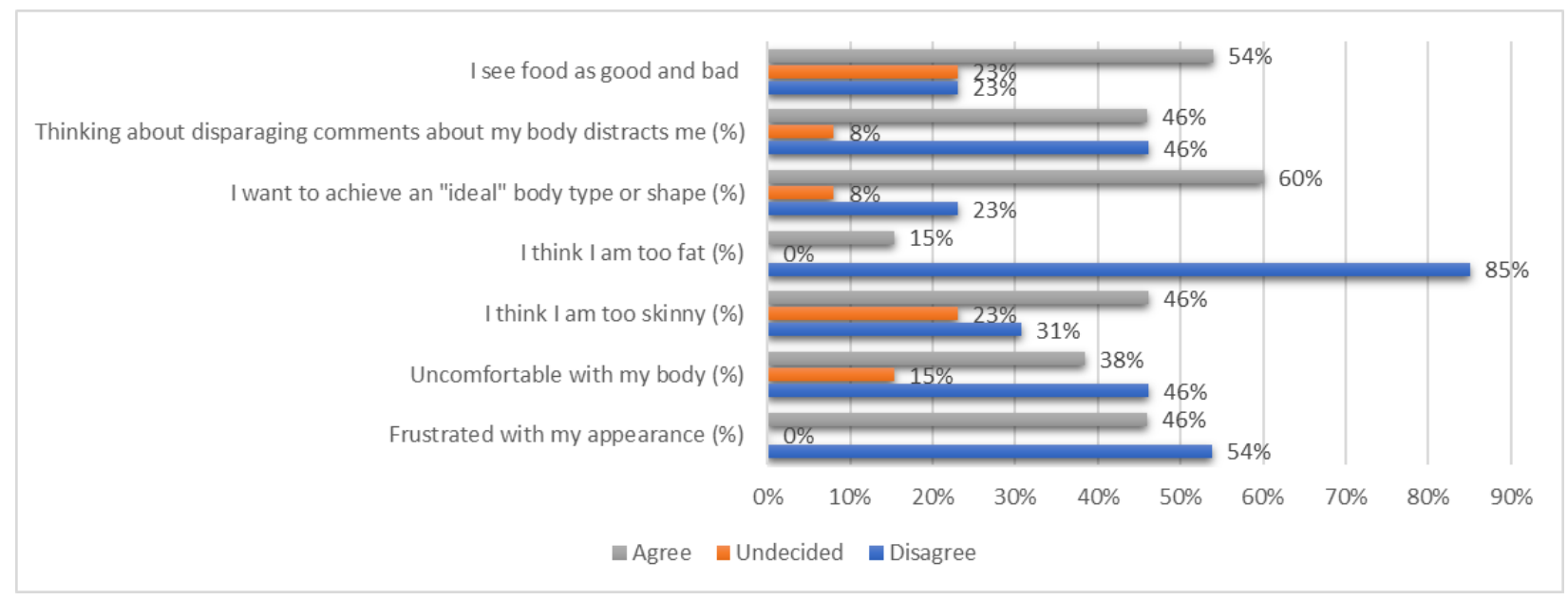

Figure 11: Body Image Perceptions of Male Adolescents at EC (Underweight)

The percentages of underweight adolescents who are frustrated and uncomfortable with one's body (42\% vs 25.45\%; Z-score: 1.370, P-Value: 0.085359 ) and distracted by frequently thinking about one's body (46\% vs $24.6 \%$; Z-score: 1.792, P-Value: 0.036607) exceed those of average male students. However, underweight students are less likely to want to achieve an "ideal" body type or shape than average students (60\% vs $73.7 \%$ ). Because the null hypothesis was not fully rejected, so being underweight was not shown to induce more body image issues among male adolescents at EC.

\section{Discussion}

Few previous studies on body image issues and ED take athletic male adolescents into the discussion. So, the researcher conducted this case study on EC's male adolescents to fill this gap. Different from females, males' body 
image issues are not primarily associated with beauty standards, but with masculine strength. Thus, strength sports were examined along with aesthetic sports for their potential influences on male adolescents.

The first four hypotheses about both kinds of sports are supported by the results. Male adolescent students who play aesthetic sports show a significant increase in the probability of having severe body image issues and perform symptoms of eating disorders than average students. Even though they have normal body weight, they are frustrated with their appearances, and some think they are too fat. The distorted understanding of healthy weight and body demonstrates the negative influences exerted on athletes by aesthetic expectations. One cheerleader wrote that "I feel like I should look stronger while I am competing." The other thinks that he feels uncomfortable with his body because "there are others who look skinnier than me." Both are pressured by other cheerleaders or the expectations of winning competitions. A dancer shares this frustration with their physiques when "perform[ing] in front of people" and when certain clothes are "form-fitting". The common theme among those responses is the pressure to pursue of flawless body type for visual pleasure in those sports. The internalization of those ideals leads to higher risks of ED as demonstrated by the fact that more than $50 \%$ of male EC students who participate in aesthetic sports show symptoms of eating disorders, mainly those of anorexia and bulimia (both incur food restriction and low body weight).

Similarly, students who play strength sports such as American football, weightlifting, and wrestling show greater susceptibility to body image issues and elevated ED risks than average students, though not as much compared to aesthetic athletes. Although less frustrated with ones' appearance, strength athletes have an intense desire to achieve an "ideal" body type. This is likely shaped by the belief that a muscular physique directly contributes to better performance in strength sports. One weightlifter believes that he feels unsatisfied with his body because "physical size (muscle mass) and body fat percentage are important to bodybuilding and other sports". An American football player agrees, sharing that "[he] might be too small to play at [his] position so [he] try working out to be bigger." Almost unanimously, strength athletes who feel insecure when playing supports think they need to gain more muscle to play well, affirming the significant influences of expectations to bulk up upon them. Also, to ensure there was no contamination of the data, the researcher examined the BMI of aesthetic and strength athletes. None of the athletes are obese, so the possibility that being overweight causes severer symptoms could be eliminated, and the validity of this finding was affirmed.

This study found that about $90 \%$ of strength athletes have dietary products at some point in the past month while more than half of them consume dietary products $50 \%$ of the time to gain muscle. Such high frequency makes providing adequate education about supplements to athletes to prevent indiscriminative intake imperative. In fact, in their 2019 study "Taking Stock of Dietary Supplements' Harmful Effects on Children, Adolescents, and Young Adults", Flora Or and his colleagues found that, among the 997 reports of health problems caused by vitamins or supplements, dietary supplements posted about three times of the risk of serious health problems of those induced by vitamins. $40 \%$ of the cases caused "trips to an emergency room, hospitalization, disability, or death" (Edwards, 2019). Though companies producing dietary supplements are supposed to "follow the FDA's current good manufacturing practices to ensure quality and safety of their product", they do not need US Food and Drug Administration (FDA) approval before putting products on to the market. As a result, addictive or hazardous ingredients might not be listed on labels, causing unconscious consumption by teens ("Sports Supplements"). In other cases, the mixed-use of supplements or combination prescription medications can incur detrimental effects (Edwards, 2019). Therefore, the lack of resources to inform teens of the health risks and educate them on ways to recognize unapproved products put increasingly more adolescents, especially males who strive for muscular physique, at risk. Thus, it is highly recommended that middle and high schools implement complementary classes to teach students about dietary supplements choices. Lastly, schools must require strength sport team instructors to conduct check-in with team members on their supplement choices regularly.

Furthermore, to put the influence of physical activity on male adolescents' body perception and eating habits into perspective, the researcher calculated the obesity's correlation with body image issue and compared the results. It was found that aesthetic sports and/or strength sports (statistically significant) have a stronger positive correlation with body image issues than weight (statistically insignificant) does. This is reflected in the participants' explanations 
of their insecurities about their bodies. Most "Obese" students do not feel insecure at all. Even when they do, it is because they feel "not as strong" rather than shameful for being plus size. For underweight participants, only $1 / 3$ of them feel insecure. Though one reported feeling uncomfortable for being the "shortest and lightest out of all" of his male friends, others feel insecure because of the aesthetic sports they participate in. This study also shows that athletic involvement has a stronger positive correlation with body image issues than weight does by shaping unrealistic or an ideal body goal.

This corroborates the previous studies on that body dissatisfaction intensifies when the discrepancy between the actual body weight and the internalized ideal weight augments rather than when body weight is higher. In other words, an athlete who is 200 pounds and has no physique expectation will have fewer body concerns than a 120 -pound gymnast that believes the ideal body to compete is 100 pounds does. So, influencing a person's perception is more important than asking overweight/obese athletes to lose weight when trying to prevent body-related mental illnesses.

The results of this study show no positive linear relationships between age and severity of body image issues and ED risks. However, 15-16-year-old male adolescents displayed a sharp increase in concerning disordered eating behaviors and negative body perceptions. This might be explained by the general trend of the heightened risks of mental health conditions around that age. According to WHO. "half of all mental health conditions start by 14 years of age" ("Adolescent mental health," 2020). Therefore, paying attention to 9th and 10th graders' mental health might be an effective way to detect and curb the development of body image issues and ED symptoms for teens at an early stage.

Future researchers should consider employing the qualitative method, such as conducting detailed interviews, to examine the associations between athletic involvement and social factors, such as family expectation and peer pressure, and their intertwined influence on body image and eating disorder issues. More reliable data will allow future researchers to make informed suggestions to help control the rapidly growing eating disorder and body image symptoms among the male population, potentially improving many people's health or even saving lives.

\section{Conclusion}

Nationwide, male teens are experiencing more body image issues and related mental illnesses than previous generations. However, the lack of research on the male population and the stigmas around men developing mental illnesses have been contributing to the limited public attention to this issue and the scarce of solutions to ameliorate it. Though some studies suggest that physical activities help restore confidence in teens by helping them losing weight or socializing, other studies conducted on athletic female college students say otherwise, pointing to intensified symptoms. Thus, the effects of aesthetic and strength sports involvement on male adolescents' mental health and body perception were explored on male students at ECHS in this study. Male teens playing aesthetic sports were found to desire a skinnier physique and use more restriction in diets, and subsequently more prone to developing anorexia or bulimia. Strength sports athletes, on the other hand, strive for bulky and masculine body types through the consumption of supplements and become prone to developing bulimia and binge eating disorders. It is highly recommended that schools require regular checkups on students' eating patterns, supplemental intake, body perception, and emotional state. This study suggests that monitoring the mental health of aesthetic sports and strength sports athletes appears to be a more effective and accurate approach to address the problem of ED risks than focusing on BMI or actual weight of students because heavier body mass was not found to be correlated with intensified body dissatisfaction. Future researchers should consider exploring similar factors on a larger population to inform school policies and adolescent mental health programs. 


\section{Limitations}

A limitation of this study is the uncertainty that all participants answered truthfully to the survey. This topic under discussion is sensitive and private, even associated with stigmas, so some students may likely feel embarrassed or reluctant to share their genuine thoughts and report real behaviors. To best eliminate the possibility of untruthful answers, all answers were received anonymously, and the participants are reassured that no personal information will be collected to protect their privacy. Participants were also requested to "answer truthfully to ensure the validity and accuracy of the study" at the beginning of the survey.

Another limitation of this study is the sampling method. Due to the busy schedule of online studying/teaching and procedure issues, conducting random sampling was very difficult. So, convenience sampling was employed to garner data. Since the study is based on a non-systematic probability sample, it is likely to be skewed towards a certain population and cannot be applied to any other population. However, the study is facilitated by the availability of test group research subjects who engage relatively actively in a wide range of sports since EC is a highly athletic school with a $75 \%$ average student sport participation rate. Thus, this case study provides a glimpse of the associations between athletic involvement and internalization of negative body image and disordered eating behaviors of male adolescents in the US.

A third limitation of the study is only 57 participants were recruited from ED, which has a 300+ male population. The small sample size undermines the representation precision. Due to the nature of the case study, the conclusions of this paper cannot be directly applied to any other population or group. However, the results provide a glimpse of the association between physical activities, body image issues, and eating disorders among male adolescents in the US. Future studies should continue to explore the implications of sports on teens' insecurities and mental health with a larger sample, ideally 1000-1500 participants if researchers want to draw conclusions on a national scale.

\section{Acknowledgments}

I would like to thank Eastside Catholic high school Religious Study department for distributing the surveys and Ms. McNesby for helping me decide on research topic and brainstorm data collection ideas.

\section{References}

Academy, U. S. (2016, April 1). Body Image Disturbances in NCAA Division I and III Female Athletes. Retrieved December 7, 2020, from http://thesportjournal.org/article/body-image-disturbances-in-ncaa-division-i-and-iii-female-athletes/.

Adolescent mental health. (2020, September 28). World Health Organization. https://www.who.int/news-room/factsheets/detail/adolescent-mental-health.

Bearman, K. S., Martinez, E., Stice, E., \& Presnell, K. (2006, April). The Skinny on Body Dissatisfaction: a longitudinal Study of Adolescent Girls and Boys. J Youth Adolescent, 35(2), 217-229.

https://www.ncbi.nlm.nih.gov/pmc/articles/PMC1540456/.

Body Image. (2018, February 22). National Eating Disorders Association. Retrieved November 20, 2020, from https://www.nationaleatingdisorders.org/body-image-0.

Brazier, Y. (2020, October 11). What is Body Image? Medical News Today. https://www.medicalnewstoday.com/articles/249190. 
Bruin, A. P., Oudejans, R. D., \& Bakker, F. C. (2007, July). Dieting and body image in aesthetic sports: A comparison of Dutch female gymnasts and non-aesthetic sport participants. Psychology of Sports and Exercise. 8(4), 507520. https://www.sciencedirect.com/science/article/pii/S1469029206001105.

Burtka, J. (2019, September 20). Body image issues can impact athletes at a young age. Global Sport Matters. https://globalsportmatters.com/health/2019/09/20/body-image-issues-can-impact-athletes-at-a-young-age/.

Eastside Catholic. An athletics program with a focus on leadership and sportsmanship. Eastside Catholic School. Retrieved March 1, 2021, from https://www.eastsidecatholic.org/athletics.

Eating Disorders in Men \& Boys. (2020, December 10). National Eating Disorders Association. Retrieved October 20, 2020, from https://www.nationaleatingdisorders.org/learn/general-information/research-on-males.

Eating Disorders. (2020, December 10). National Institute of Mental Health. Retrieved October 15, 2020, from https://www.nimh.nih.gov/health/topics/eating-disorders/index.shtml.

Edwards, E. (2019, June 4). Teenagers can be seriously harmed by dietary supplements. NBC News. https://www.nbcnews.com/health/kids-health/teenagers-can-be-seriously-harmed-dietary-supplements-n1013696.

Fairburn G. C., Cooper Z., \& O’Connor, M. Eating Disorder Examination. Credo-Oxford. Retrieved March 10, 2021, from https://www.credo-oxford.com/pdfs/EDE 17.0D.pdf.

Fitbit Staff. (2020, March 23). The Impact Of Coronavirus On Global Activity. Fitbit. https://blog.fitbit.com/covid19-global-activity/.

Gallivan, H. (2014). Teens, Social Media and Body Image. Park Nicollet Melrose Center. Retrieved from https://www.macmh.org/wp-ontent/uploads/2014/05/18 Gallivan Teens-social-media-body-image-presentation-HGallivan-Spring-2014.pdf.

Heale R. \& Twycross, A. (2017). What is a case study? Evidence-Based Nursing., 21, 1, November 2017. http://dx.doi.org/10.1136/eb-2017-102845.

Insel, T. (2012, February 24). Post by Former NIMH Director Thomas Insel: Spotlight on Eating Disorders. National Institute of Mental Health. https://www.nimh.nih.gov/about/directors/thomas-insel/blog/2012/spotlight-oneating-disorders.shtml.

Izydorczyk, B., \& Sitnik-Warchulska, K. (2018, March 29). Sociocultural Appearance Standards and Risk Factors for Eating Disorders in Adolescents and Women of Various Ages. Frontiers in Psychology, 9(429).

https://doi.org/10.3389/fpsyg.2018.00429.

Kimm, S. Y., Glynn, N. W., Kriska, A. M., Barton, B. A., Kronsberg, S. S., Daniels, S. R., Crawford, P. B., Sabry, Z. I., \& Liu, K. (2002). Decline in physical activity in black girls and white girls during adolescence. The New England journal of medicine, 347(10), 709-715. https://doi.org/10.1056/NEJMoa003277.

Kypri, K., Sonneville, K. R., Crosby, R. D., Swanson, S. A., Eddy, K.T., Camargo, C. A., Horton, N. J., \& Micali, A. (2014, January). Prospective Associations of Concerns About Physique and the Development of Obesity, Binge 
Drinking, and Drug Use Among Adolescent Boys and Young Adult Men. JAMA Pediatr. 168(1), 34-39. https://jamanetwork.com/journals/jamapediatrics/fullarticle/1766495.

Lipson, S. K., \& Sonneville, K. R. (2017). Eating disorder symptoms among undergraduate and graduate students at 12 U.S. colleges and universities. Eating behaviors, 24, 81-88. https://doi.org/10.1016/j.eatbeh.2016.12.003.

Maier, S. (2020, July 1). Physical Activity Dropped Worldwide During COVID-19, Raising Concerns for Health. University of California San Francisco. https://www.ucsf.edu/news/2020/07/417951/physical-activity-droppedworldwide-during-covid-19-raising-concerns-health.

McCabe, M., \& Ricciardelli, L. (2004). A Longitudinal study of pubertal timing and extreme body change behaviors among adolescent boys and girls. Adolescence, 39(153), 145-166. http://dro.deakin.edu.au/view/DU:30002525.

McKay, P. S., \& Read, M. S. (1997, January 1). Adolescent Male Athletes: Body Image, Diet, and Exercise. https://search.proquest.com/docview/1295898260/5E797F0FFEC04D48PQ/1.

Mountford, V. A., \& Koskina, A. (2015, November 21). Body Image. Encyclopedia of Feeding and Eating Disorders. https://ink.springer.com/referenceworkentry/10.1007\%2F978-981-287-087-2 74-1.

Part 2: Effects of a Negative Body Image. (2019, January 22). Perspectives Counseling Centers. Retrieved November 29, 2020, from https://perspectivesoftroy.com/effects-negative-body-image/.

Pavao, S. L. (2013, May 6). Differences in Body Dissatisfaction in Male Collegiate Athletes. BSU Honors Program Theses and Projects. http://vc.bridgew.edu/honors proj/7.

Sports Supplements. TeensHealth. Reviewed by Amy W. Anzilotti. Retrieved March 10, 2021, from https://kidshealth.org/en/teens/sports-supplements.html.

Strother, E., Lemberg, R., Stanford, S. C., \& Turberville, D. (2012, September 17). Eating disorders in men: underdiagnosed, undertreated, and misunderstood. Eating disorders, 20(5), 346-355. https://doi.org/10.1080/10640266.2012.715512.

Team Rawhide. (2016, April 26). Body Image Issues: The Teen Male Edition [Inforgraphic]. Rawhide. Retrieved September 27, 2020. https://www.rawhide.org/blog/infographics/body-image-issues/.

Voelker, D. K., Reel, J. J., \& Greenleaf, C. (2015). Weight status and body image perceptions in adolescents: current perspectives. Adolescent health, medicine and therapeutics, 6, 149-158. https://doi.org/10.2147/AHMT.S68344.

Weight \& Body Image Disorders: Causes, Symptoms \& Signs. (2020, September 30). Eating Disorder Hope. Retrieved November 23, 2020, from https://www.eatingdisorderhope.com/information/body-image\#: : :text=What $\% 20$ is $\% 20$ Negative $\% 20$ or $\% 20$ Distorted,also $\% 20$ suffer $\% 20$ from $\% 20$ the $\% 20$ disorder 